\title{
CLINICAL EVALUATION OF MANAGEMENT AND PREVALENCE OF TYPE TWO DIABETES MELLITUS COMPLICATIONS IN SOUTH INDIAN POPULATION
}

\author{
GEETHA P*, SHANMUGASUNDARAM P \\ Department of Pharmacy Practice, Vels Institute of Science, Technology and Advanced Studies, Tamil Nadu, India. \\ Email: lgeethapharma@gmail.com
}

Received: 10 October 2018, Revised and Accepted: 11 December 2018

\begin{abstract}
Objective: The present study was aimed to assess the prevalence of complications and to assess the targets achieved during the management of diabetes mellitus type 2 .

Methods: The study was prospective and conducted out in a diabetes center, Chennai, ethical approval was obtained from the Institutional Ethics Committee, case records of the 300 patients diagnosed with type 2 diabetes mellitus and its complications were monitored during March 2017-April 2018. Major result actions are body weight, height, body mass index (BMI), blood pressure, fasting blood sugar (FBS), post-prandial blood sugar (PPBS) levels, glycosylated hemoglobin, serum lipids, and presence of complications of diabetes. Comparison of the average of various biochemical parameters was made in patients with and no diabetic complications.
\end{abstract}

Results: The average age of 300 patients was found to be $55.006 \pm 13.04$. The average BMI was $27.10 \pm 12.81 \mathrm{~kg} / \mathrm{m}^{2}$. The average duration of diabetes was $10.48 \pm 7.53$. The average of systolic (SBP) and diastolic blood pressure was $137 \pm 20.88$ and $79.95 \pm 11.81$. The mean glycated hemoglobin, FBS, PPBS, low-density lipoprotein, high-density lipoprotein, and triglyceride, and total cholesterol were found to be $8.5 \pm 3.99,148.85 \pm 55.64 \mathrm{mg} / \mathrm{dl}$, $200.98 \pm 72.63 \mathrm{mg} / \mathrm{dl}, 88.06 \pm 19.46 \mathrm{mg} / \mathrm{dl}, 36.20 \pm 8.27 \mathrm{mg} / \mathrm{dl}, 141.22 \pm 60.15 \mathrm{mg} / \mathrm{dl}$, and $144.45 \pm 29.03 \mathrm{mg} / \mathrm{dl}$, respectively. Among the microvascular complications; neuropathy, nephropathy, and retinopathy were documented in $8.33 \%, 23.66 \%$, and $17.33 \%$ of patients, respectively. The prevalence of peripheral artery disease was $20.66 \%$.

Conclusion: The prevalence of diabetic complications is significantly increased with patients age, duration, SBP, low-density lipoprotein, total cholesterol, and post-prandial blood sugar levels. Knowledge concerning the supervision of target blood pressure and lipid parameters is need further than the glycemic manage among diabetes patients type two.

Keywords: Glycosylated hemoglobin, Fasting blood sugar, Post-prandial blood sugar.

(C) 2018 The Authors. Published by Innovare Academic Sciences Pvt Ltd. This is an open access article under the CC BY license (http://creativecommons. org/licenses/by/4. 0/) DOI: http://dx.doi.org/10.22159/ajpcr.2018.v11s4.31733

\section{INTRODUCTION}

Efficient supervision of diabetes needs continued glycemic control over several days to lesser the possibility of micro- and macro-vascular problems of diabetes. The UK prospective diabetes study established to each $1 \%$ decrease in glycosylated hemoglobin (HbA1c) be linked by means of a $37 \%$ reduction in micro- and macro-vascular complications and a $14 \%$ decline in myocardial infarction [1]. Although intensive glycemic control lowers the frequency and development of microvascular complications, the morbidity associated with these complications is still increasing [2]. Nowadays, more concentration has been given to the managing of large blood vessel problems, for example, cerebrovascular accident and acute coronary syndromes. It is finely recognized that blood vessel complication within a specified tissue can be frequently accompany by confirmation of pathology in other vascular territories. A linear association among small blood vessel complications and length of illness can be recognized by the authors where they acknowledged the occurrence of microvasculopathy across various age groups in their study in $25-40 \%$ of diabetic patients aged $>25$ years with a duration of diabetes was above 5 years [3]. One of the important risk factors for diabetes is obesity, so far very few research work focusing on obesity as one of the risk factor across India [4]. Even though the patients having reduced overweight and body mass index (BMI) rates, the prevalence of diabetes was highest in India when compared to western countries signifying that diabetes might arise on many Indian people with lower BMI comparison with Europeans [4,5]. As a result, comparatively, adult with low body weight and lower BMI could be next to equivalent danger when persons who are overweight [6]. Moreover, Indians are hereditarily disposed to the progress of coronary heart disease due to dyslipidemia, and high-density lipoprotein (HDL) levels are low [7]. Timely remedial actions, goal to become stable blood glucose levels along with a decline in low-density lipoprotein and triglycerides as well as to boost HDL, considerably decrease adverse events on heart and death of type two diabetes [8]. Our study was designed to check the desired results attained in the supervision of diabetes mellitus type two and to learn the occurrence of complications in South Indian Population.

\section{METHODS}

A prospective study of type 2 diabetic patients was carried out in a private diabetic center, Chennai with 300 outpatients, the study was approved by the Institutional Ethics Committee (Ref: IEC/PHD/2015/2016/01), Vels Institute of Science, Technology and Advanced Studies (VISTAS) and conducted based on the inclusion and exclusion criteria. Inclusion criteria are based on type 2 diabetes either fasting blood sugar (FBS) $>125 \mathrm{mg} / \mathrm{dl}$ or post-prandial blood sugar (PPBS) $>200 \mathrm{mg} / \mathrm{dl}$, a patient who agreed to check for complications of diabetes 2 mellitus, patients with regular follow-up and treatment. We excluded the patients, those who are present with type 1 diabetes mellitus, diabetic pregnant women, people are not willing to participate, patients who were not under regular treatment. All demographic and clinical data of patients such as FBS, PPBS, HbA1c, low-density lipoprotein (LDL), very LDL, HDL, and total cholesterol were collected and documented in a suitably designed case extraction form. Suggestion from the eye specialist was obtained to check the condition of retinopathy through using fundoscopy. Vibration 
perception test carries out to identify the presence of neuropathy. Renal function tests, particularly, microalbuminuria were performed to identify the presence of nephropathy. Peripheral arterial disease was identified by checking the ankle brachial index. The guidelines framed by Indian Council of Medical Research in the year 2005 in connection through the World Health Organization be used to categorize the targets achieved in the patients (Table 1).

\section{Statistical analysis}

Statistical analysis was carried out using Microsoft Excel and GraphPad Prism. Average and standard deviation were calculated for biochemical parameters. Comparison of means of every parameter of the group with and without complications was studied.

Table 1: Targets in the management of type 2 diabetes mellitus (Indian Council of Medical Research guidelines 2005)

\begin{tabular}{llll}
\hline Parameter & $\begin{array}{l}\text { Ideal } \\
\text { (target) }\end{array}$ & $\begin{array}{l}\text { Satisfactory } \\
\text { (fair) }\end{array}$ & $\begin{array}{l}\text { Unsatisfactory } \\
\text { (poor) }\end{array}$ \\
\hline FBS (mg/dl) & $80-110$ & $111-125$ & $>125$ \\
PPBS (mg/dl) & $120-140$ & $140-180$ & $>180$ \\
Glycated hemoglobin (\%) & $<7 \%$ & $7-8 \%$ & $>8 \%$ \\
Blood pressure (mmHg) & $<130 / 80$ & $<140 / 90$ & $>140 / 90$ \\
BMI (kg/m ${ }^{2}$ ) & $20-23$ & Nil & Nil \\
Total cholesterol (mg/dl) & $<180$ & Nil & Nil \\
LDL (mg/dl) & $<100$ & Nil & Nil \\
HDL (mg/dl) & $>45$ & Nil & Nil \\
Triglycerides (mg/dl) & $<150$ & Nil & Nil \\
\hline
\end{tabular}

HDL: High-density lipoprotein, FBS: Fasting blood sugar, PPBS: Post-prandial blood sugar, BMI: Body mass index, LDL: Low-density lipoprotein

\section{RESULTS}

A prospective study was carried out with 300 outpatients in a diabetes center. The average age of 300 participants was calculated to be $55.006 \pm 13.04$. The average BMI was $27.10 \pm 12.81 \mathrm{~kg} / \mathrm{m}^{2}$. The average duration of diabetes was $10.48 \pm 7.53$. The average of systolic and diastolic blood pressure (SBP and DBP) was $137 \pm 20.88$ and 79.95 \pm 11.81 . The mean glycated A1c, FBS, PPBS, low and HDL, and triglyceride, and total cholesterol were found to be $8.5 \pm 3.99,148.85 \pm$ $55.64 \mathrm{mg} / \mathrm{dl}, \quad 200.98 \pm 72.63 \mathrm{mg} / \mathrm{dl}, \quad 88.06 \pm 19.46 \mathrm{mg} / \mathrm{dl}, 36.20 \pm$ $8.27 \mathrm{mg} / \mathrm{dl}, 141.22 \pm 60.15 \mathrm{mg} / \mathrm{dl}$, and $144.45 \pm 29.03 \mathrm{mg} / \mathrm{dl}$, respectively. Among the microvascular complications; neuropathy, nephropathy, and retinopathy were documented in $8.33 \%, 23.66 \%$ (Table 2), and $17.33 \%$ (Table 3) of patients, respectively. The prevalence of peripheral artery disease was $20.66 \%$ (Table 3).

In type 2 diabetes mellitus, an average of every clinical parameter in the group with complication was compared to nil complication was studied. Table 2 represents the prevalence of with neuropathy and without correlates statistically significant with PPBS and HDL values, the prevalence of with nephropathy and without nephropathy highly significant with SBP, FBS, PPBS, total cholesterol, and LDL. Table 3 represents the prevalence of with retinopathy or without retinopathy highly significantly with age, SBP, FBS, PPBS, total cholesterol, and LDL but the prevalence of peripheral arterial disease not significant with any of the parameters. Table 4 represents the achievements of targets of various clinical and biochemical parameters according to the ICMR 2005 guidelines. All the patients were interested in controlling body weight and blood pressure control but the majority of the patients not achieved the targets of controlling blood sugar levels.

Table 2: Comparison of means of different parameters in the presence or absence group of neuropathy and nephropathy

\begin{tabular}{|c|c|c|c|c|c|c|}
\hline \multirow[t]{2}{*}{ Complications parameters } & \multicolumn{3}{|l|}{ Neuropathy } & \multicolumn{3}{|l|}{ Nephropathy } \\
\hline & Present $n=52$ & Absent $n=248$ & $p$ value & Present $n=71$ & Absent $n=229$ & p value \\
\hline Age (years) & $57.08 \pm 14.39$ & $54.82 \pm 12.93$ & 0.40 & $57.34 \pm 12.68$ & $54.28 \pm 13.10$ & 0.084 \\
\hline SBP (mmHg) & $144.52 \pm 18.10$ & $136.32 \pm 21.01$ & 0.06 & $144.90 \pm 18.19$ & $134.55 \pm 21.09$ & $0.0002 * *$ \\
\hline DBP (mmHg) & $82.76 \pm 8.72$ & $79.69 \pm 12.04$ & 0.21 & $81.65 \pm 14.41$ & $79.42 \pm 10.87$ & 0.165 \\
\hline BMI & $27.10 \pm 3.55$ & $27.04 \pm 4.89$ & 0.95 & $27.36 \pm 5.27$ & $27.82 \pm 14.37$ & 0.79 \\
\hline HbA1c (\%) & $8.96 \pm 2.23$ & $8.46 \pm 4.12$ & 0.55 & $8.98 \pm 2.41$ & $8.35 \pm 4.36$ & 0.245 \\
\hline FBS (mg/dl) & $164.48 \pm 61.89$ & $147.42 \pm 54.94$ & 0.14 & $162.53 \pm 63.11$ & $144.60 \pm 52.55$ & $0.01^{*}$ \\
\hline PPBS (mg/dl) & $229.06 \pm 72.49$ & $198.40 \pm 72.09$ & 0.04 & $224.28 \pm 89.10$ & $193.47 \pm 65.19$ & $0.001^{* *}$ \\
\hline Total cholesterol (mg/dl) & $153.08 \pm 25.53$ & $143.67 \pm 29.25$ & 0.12 & $153.51 \pm 32.83$ & $141.65 \pm 27.22$ & $0.0025^{*}$ \\
\hline $\mathrm{LDL}(\mathrm{mg} / \mathrm{dl})$ & $89.64 \pm 17.69$ & $82.46 \pm 19.54$ & 0.077 & $88.90 \pm 25.03$ & $81.25 \pm 17.04$ & $0.003^{* *}$ \\
\hline HDL (mg/dl) & $32.50 \pm 9.83$ & $36.43 \pm 8.11$ & $0.02 * 3$ & $36.07 \pm 7.12$ & $36.25 \pm 8.62$ & 0.87 \\
\hline Triglycerides (mg/dl) & $161.64 \pm 65.95$ & $138.60 \pm 55.80$ & 0.09 & $149.61 \pm 56.89$ & $139.01 \pm 60.42$ & 0.191 \\
\hline
\end{tabular}

HDL: High-density lipoprotein, FBS: Fasting blood sugar, PPBS: Post-prandial blood sugar, BMI: Body mass index, LDL: Low-density lipoprotein, SBP: Systolic blood pressure, DBP: Diastolic blood pressure

Table 3: Comparison of means of different parameters in the presence or absence group of retinopathy and peripheral arterial disease

\begin{tabular}{|c|c|c|c|c|c|c|}
\hline \multirow[t]{2}{*}{ Complications parameters } & \multicolumn{3}{|l|}{ Retinopathy } & \multicolumn{3}{|c|}{ Peripheral arterial disease } \\
\hline & Present $n=52$ & Absent $n=248$ & p value & Present $n=62$ & Absent $n=238$ & p value \\
\hline Age (years) & $65.58 \pm 11.8$ & $52.79 \pm 12.19$ & $0.0001^{* *}$ & $52.20 \pm 13.52$ & $54.95 \pm 12.94$ & 0.893 \\
\hline Duration (years) & $11.58 \pm 8.10$ & $10.14 \pm 7.33$ & 0.159 & $10.53 \pm 8.04$ & $10.47 \pm 7.40$ & 0.955 \\
\hline $\mathrm{SBP}(\mathrm{mmHg})$ & $144.90 \pm 18.19$ & $134.55 \pm 21.09$ & $0.0002^{* *}$ & $134.58 \pm 24.23$ & $137.63 \pm 19.92$ & 0.306 \\
\hline $\mathrm{DBP}(\mathrm{mmHg})$ & $81.65 \pm 14.41$ & $79.42 \pm 10.87$ & 0.165 & $81.35 \pm 9.66$ & $79.58 \pm 12.30$ & 0.294 \\
\hline BMI & $27.36 \pm 5.27$ & $27.82 \pm 14.37$ & 0.79 & $27.23 \pm 4.61$ & $26.95 \pm 4.83$ & 0.681 \\
\hline HbA1c(\%) & $8.98 \pm 2.41$ & $8.35 \pm 4.36$ & 0.245 & $8.12 \pm 2.27$ & $8.60 \pm 4.32$ & 0.399 \\
\hline FBS (mg/dl) & $162.53 \pm 63.11$ & $144.60 \pm 52.55$ & $0.01^{*}$ & $141.46 \pm 40.83$ & $150.77 \pm 58.81$ & 0.241 \\
\hline PPBS (mg/dl) & $224.28 \pm 89.10$ & $193.47 \pm 65.19$ & $0.001^{* *}$ & $190.82 \pm 49.64$ & $203.63 \pm 77.39$ & 0.216 \\
\hline Total cholesterol (mg/dl) & $153.51 \pm 32.83$ & $141.65 \pm 27.22$ & $0.0025^{* *}$ & $141.14 \pm 27.41$ & $145.31 \pm 29.43$ & 0.314 \\
\hline LDL (mg/dl) & $88.90 \pm 25.03$ & $81.25 \pm 17.04$ & $0.003^{* *}$ & $82.40 \pm 19.58$ & $83.23 \pm 19.47$ & 0.765 \\
\hline HDL (mg/dl) & $36.07 \pm 7.12$ & $36.25 \pm 8.62$ & 0.87 & $37.09 \pm 8.79$ & $35.97 \pm 8.14$ & 0.343 \\
\hline Triglycerides (mg/dl) & $149.61 \pm 56.89$ & $139.01 \pm 60.42$ & 0.191 & $133.35 \pm 41.27$ & $141.58 \pm 59.10$ & 0.302 \\
\hline
\end{tabular}

HDL: High-density lipoprotein, FBS: Fasting blood sugar, PPBS: Post-prandial blood sugar, BMI: Body mass index, LDL: Low-density lipoprotein, SBP: Systolic blood pressure, DBP: Diastolic blood pressure 
Table 4: Targets achieved in the management of important parameters of diabetes

\begin{tabular}{lllllll}
\hline Number of patients & Parameter & FBS & PPBS & HbA1C & BMI & LDL \\
\hline All patients & Ideal & 75 & 51 & 96 & 63 & 224 \\
& Satisfactory & 48 & 93 & 76 & 170 & - \\
& Unsatisfactory & 177 & 156 & 128 & 67 & 56 \\
\hline
\end{tabular}

HDL: High-density lipoprotein, FBS: Fasting blood sugar, PPBS: Post-prandial blood sugar, BMI: Body mass index, LDL: Low-density lipoprotein, SBP: Systolic blood pressure, DBP: Diastolic blood pressure

\section{DISCUSSION}

Our study was aimed to evaluate the diabetes treatment and to learn the occurrence of a problem in this hospital system. This current study indicates that the higher prevalence of diabetic complications such as neuropathy, nephropathy, and retinopathy was documented in $8.33 \%, 23.66 \%$, and $17.33 \%$ of patients, respectively. The prevalence of peripheral artery disease was $20.66 \%$. A study conducted by Arambewela et al., in Sri Lanka microvascular complications such as retinopathy, nephropathy, and neuropathy reported as $26.1 \%, 50.8 \%$, and $62.6 \%$ and macrovascular complications such as peripheral vascular disease reported as $4.2 \%$. The results of our study were compared to Sri Lankan diabetes people, prevalence of complications was lower in our study [9]. The diabetes complications and control trial recognized $<7 \%$ of glycated hemoglobin levels suitable for decreasing the possibility of blood vessel related problems and as well the gold standard of blood glucose control [10]. Glycated hemoglobin was greater than $8 \%$ in all the diabetic complications of our study. The similar study by Unnikrishnan et al. studied in 480 patients among personally reported type two diabetes (urban 254 and 226 rural), the average levels of glycated hemoglobin were maximum of $9.1-2.3 \%$ in Chandigarh, followed by $8.2-2.0 \%$ in Tamil Nadu, $8.2-2.4 \%$ in Jharkhand, and $8.0-2.1 \%$ in Maharashtra [11]. In our study, severity of retinopathy, nephropathy, and peripheral arterial disease was increased with the duration and increased HbA1c levels. The study conducted by Samantha et al., the severity of retinopathy and neuropathy was related to the longer duration of diabetes and high levels of glycosylated hemoglobin. The incidence of retinopathy was significantly increased with the duration of the diabetes mellitus, and it was associated with a poor glycemic control [12]. In our study, the values for FBS and PPBS were increased in patients with diabetic complications. The similar studies results reported that considerably higher levels of FBS, total cholesterol, triglycerides, and low-density lipoprotein achieved with patients of poor and worse control [13-15]. Another study by Haghighatpanah et al. reported PPBS had a closer association with HbA1c and better predictor for overall glycemic control [16].

\section{CONCLUSION}

The present work ensures the prevalence of complications and poor blood glucose control of type 2 diabetes mellitus considerably raised with patients age, duration, SBP, LDL, total cholesterol, and post-prandial blood sugar levels. Hence, the management of blood pressure, blood sugar levels, HbA1c, and lipid profile are necessary to avoid the life frightening problems such as the atherosclerotic heart. Awareness about the disease and education is necessary to prevent their progression.

\section{ACKNOWLEDGMENTS}

The authors would like to thank Aruna Diabetes Centre, Choolaimedu, Chennai.

\section{CONFLICTS OF INTEREST}

Declared none.

\section{REFERENCES}

1. Stratton IM, Adler AI, Neil HA, Matthews DR, Manley SE, Cull CA, et al. Association of glycaemia with macrovascular and microvascular complications of Type 2 diabetes (UKPDS 35): Prospective observational study. BMJ 2000;321:405-12.

2. ADVANCE Collaborative Group; Patel A, MacMahon S, Chalmers J, Neal B, Billot L, et al. Intensive blood glucose control and vascular outcomes in patients with Type 2 diabetes. N Engl J Med 2008;358:2560-72.

3. Chawla A, Chawla R, Bhasin GK, Soota K. Profile of adolescent diabetes in North Indian population. J Clin Diabetol 2014;1:1-3.

4. Rao CR, Kamath VG, Shetty A, Kamath A. A cross-sectional analysis of obesity among a rural population in coastal Southern Karnataka, India. Australas Med J 2011;4:53-7.

5. Mohan V, Deepa R. Obesity and abdominal obesity in Asian Indians. Indian J Med Res 2006;123:593-6.

6. Zargar AH, Khan AK, Masoodi SR, Laway BA, Wani AI, Bashir MI, et al. Prevalence of Type 2 diabetes mellitus and impaired glucose tolerance in the Kashmir valley of the Indian subcontinent. Diabetes Res Clin Pract 2000;47:135-46.

7. Misra A, Khurana L. Obesity-related non-communicable diseases: South Asians vs white caucasians. Int J Obes (Lond) 2011;35:167-87.

8. Jones PH. Clinical significance of recent lipid trials on reducing risk in patients with Type 2 diabetes mellitus. Am J Cardiol 2007;99:133B-140B.

9. Arambewela MH, Somasundaram NP, Jayasekara HB, Kumbukage MP, Jayasena PM, Chandrasekara $\mathrm{P}$, et al. Prevalence of chronic complications, their risk factors, and the cardiovascular risk factors among patients with Type 2 diabetes attending the diabetic clinic at a tertiary care hospital in Sri Lanka. J Diabetes Res 2018;2018:10.

10. DCCT Research Group. The absence of a glycemic threshold for the development of long-term complications: The perspective of the diabetes control and complications trial. Diabetes 1996;45:1289-98.

11. Unnikrishnan R, Anjana RM, Deepa M, Pradeepa R, Joshi SR, Bhansali A, et al. Glycemic control among individuals with selfreported diabetes in India - the ICMR-INDIAB study. Diabetes Technol Ther 2014;16:596-603.

12. Samantha P, Venkateswaralu M, Praboth S. The role of biochemical markers in the prediction of microvascular complications in Type-2 diabetes mellitus 2011. J Clin Diagn Res 2011;6:1154-57.

13. Ladeia AM, Adan L, Couto-Silva AC, Hiltner A, Guimarães AC. Lipid profile correlates with glycemic control in young patients with Type 1 diabetes mellitus. Prev Cardiol 2006;9:82-8.

14. Huang ES, Meigs JB, Singer DE. The effect of interventions to prevent cardiovascular disease in patients with Type 2 diabetes mellitus. Am J Med 2001;111:633-42.

15. Hanefeld M, Fischer S, Julius U, Schulze J, Schwanebeck U, Schmechel $\mathrm{H}$, et al. Risk factors for myocardial infarction and death in newly detected NIDDM: The diabetes intervention study, 11-year follow-up. Diabetologia 1996;39:1577-83.

16. Haghighatpanah M, Thunga G, Khare S, Mallayasamy S. Correlation of glycosylated hemoglobin levels with fasting and postprandial glucose in South Indian Type 2 diabetic patients. Int J Pharm Pharm Sci 2016;8:285-8. 